\title{
Storm-time meridional flows: a comparison of CINDI observations and model results
}

\author{
M. Hairston ${ }^{1}$, N. Maruyama $^{2}$, W. R. Coley ${ }^{1}$, and R. Stoneback ${ }^{1}$ \\ ${ }^{1}$ Center for Space Sciences, University of Texas at Dallas, Richardson, TX, USA \\ ${ }^{2}$ CIRES, University of Colorado, and NOAA Space Weather Prediction Center, Boulder, CO, USA \\ Correspondence to: M. Hairston (hairston@utdallas.edu)
}

Received: 15 November 2013 - Revised: 26 March 2014 - Accepted: 3 April 2014 - Published: 17 June 2014

\begin{abstract}
During a large geomagnetic storm, the electric field from the polar ionosphere can expand far enough to affect the mid-latitude and equatorial electric fields. These changes in the equatorial zonal electric field, called the penetration field, will cause changes in the meridional ion flows that can be observed by radars and spacecraft. In general this $\boldsymbol{E} \times \boldsymbol{B}$ ion flow near the equator caused by the penetration field during undershielding conditions will be upward on the dayside and downward on the nightside of the Earth. Previous analysis of the equatorial meridional flows observed by CINDI instrument on the C/NOFS spacecraft during the 26 September 2011 storm showed that all of the response flows on the dayside were excess downward flows instead of the expected upward flows. These observed storm-time responses are compared to a prediction from a physics-based coupled model of thermosphere-ionosphereinner-magnetosphere in an effort to explain these observations. The model results suggest that the equatorial downward flow could be attributed to a combined effect of the overshielding and disturbance dynamo processes. However, some discrepancy between the model and observation indicates a need for improving our understanding of how sensitive the equatorial electric field is to various model input parameters that describe the magnetosphere-ionosphere coupling processes.
\end{abstract}

Keywords. Ionosphere (equatorial ionosphere; magnetosphere-ionosphere interactions; modeling and forecasting)

\section{Introduction}

Equatorial ionospheric plasma $\boldsymbol{E} \times \boldsymbol{B}$ drift can be disturbed by the solar-wind-magnetospheric interaction during a storm. Generally the region 2 field aligned currents associated with pressure gradients near the inner edge of the plasmasheet tend to shield the mid- and low-latitude ionosphere from the region 1 field aligned currents associated with the driving dawn-to-dusk convection electric field (e.g., Jaggi and Wolf, 1973). But a sudden increase (decrease) in the strength of the convection field most commonly caused by southward (northward) turnings of the interplanetary magnetic field (IMF) $B_{z}$ component, can occur faster than the ring current particles can reconfigure itself in response to the driving field to shield the low- and mid-latitude ionosphere. Thus an excess electric field can appear in the mid- and lowlatitude regions that is referred to as an undershielding (overshielding) condition (e.g., Wolf et al., 1982; Kelley, 1989) and is sometime referred to as a penetration field. On the dayside of the Earth this penetration electric field during undershielding condition produces an excess eastward electric field near the equator that in turn causes an excess $\boldsymbol{E} \times \boldsymbol{B}$ upward motion of the ions in the ionosphere. Conversely on the nightside this produces an excess westward electric field causing a downward flow of ions. This excess upward (downward) flow on the dayside (nightside) after a geomagnetic storm onset has been observed by radar (e.g., Kelley et al., 2003; Huang et al., 2005; Fejer et al., 2007) and satellite measurements (e.g., Fejer et al., 2008; Huang, 2008).

Another process that disturbs the equatorial ionospheric electric field comes from the storm-time neutral wind. The thermospheric wind disturbance, largely driven by Joule heating and ion drag at high latitudes, generates the ionospheric wind dynamo electric field during storms called the 
disturbance dynamo (DD) process (Blanc and Richmond, 1980). Its effects are largest in the mid- and low-latitude ionosphere and thermosphere where direct forcing from the magnetosphere is weak. The main driver of the DD process is considered to be winds in the dynamo region (90-200 km) that have expanded equatorward from the auroral region. The equatorward wind transports angular momentum, resulting in a westward wind at mid-latitude due to the Coriolis effect. Charge buildup produces a poleward directed electric field (a westward $\boldsymbol{E} \times \boldsymbol{B}$ drift), which then balances the equatorward Pedersen current driven by the westward wind. In addition, the westward wind also produces an eastward Hall current, which creates charge buildup in the zonal direction opposite from that during quiet time. This results in an east-west electric field in the lower latitudes that is westward (eastward) on the dayside (nightside) that would cause downward (upward) ion flows, just the opposite effect caused by the penetration field described above. The general timescale of the DD electric field is several hours, since the disturbed zonal wind takes time to develop (Blanc and Richmond, 1980). An additional, relatively fast timescale of $2-3 \mathrm{~h}$ was reported by Scherliess and Fejer (1997), and the mechanism is attributed to an equatorward surge of the neutral wind (Fuller-Rowell et al., 2008; Maruyama et al., 2005).

This study began as an attempt to identify and quantify these predicted upward ion flows associated with the prompt penetration in the dayside equatorial ionosphere after the onset of a geomagnetic storm using the data from the Coupled Ion-Neutral Dynamics Investigation (CINDI) science instruments on board the Communications/Navigation Outage Forecast System (C/NOFS) spacecraft. Previous work using the ion flow database from CINDI during the quiet times of the extended solar minimum from 2008 through 2010 showed a general pattern of both upward and downward flows on the dayside depending on the longitude, local time, and season of the observations (Stoneback et al., 2011). It was not until mid-2011, three years after the launch of $\mathrm{C} / \mathrm{NOFS}$, that storms began to occur which were large enough to produce penetration fields significant enough to be observed in the equatorial region. One of the first of these storms occurred on 26 September 2011 and we have done a detailed analysis of the vertical and meridional flows observed by CINDI that were associated with that storm (Hairston et al., 2013). The surprising result of this study was that no excess upward flows were observed at all. Instead, the flows just prior to the storm onset, soon after the storm onset, and for almost $24 \mathrm{~h}$ after the storm onset, all showed excess downward motions of varying magnitudes. In this paper we take the observations from that study and then interpret this phenomenon by using a first principles model that self-consistently couples the magnetosphereionosphere-thermosphere system.

\section{C/NOFS-CINDI data}

The CINDI instrument suite contains an ion drift meter and retarding potential analyzer that together measure the full three-dimensional ion flow vector along with the ion density, temperature and composition at a cadence of once per second. The ion flows are measured in the spacecraft's frame of reference. For this work we use the following coordinate system: $+x$ is the direction of the spacecraft's velocity with positive oriented eastward, $+y$ is the horizontal cross track direction with positive oriented northward, and $+z$ is vertical with positive oriented upward. Using the Earth's magnetic field at the location of the spacecraft, the ion flows are also converted into a magnetic coordinate where the zonal flow is horizontal at right angles to the field line (positive is eastward), the parallel flow is parallel to the field line (positive is northward), and the meridional flow is vertical at right angles to the field line (positive is upwards). The term "meridional" can be confusing when used in the sense of vertical motion rather the more traditional usage (north-south motion) but this usage is common in equatorial ionospheric studies. This comes from the fact that motion of a magnetic field line in the north-south plane near its foot at higher latitudes translates to a motion in the vertical plane of the field line in the equatorial regions. The C/NOFS spacecraft was launched in spring 2008 into an orbit inclined $13^{\circ}$ to the equator with an initial apogee of $\sim 830 \mathrm{~km}$ and perigee of $\sim 400 \mathrm{~km}$. With the 67-day precession of the apogee through all solar local times (SLT) this has created a four-year database of observations of the equatorial ionosphere between $+13^{\circ}$ and $-13^{\circ}$ latitude, between $\sim 400$ and $\sim 800 \mathrm{~km}$ in altitude, and covering all local times and longitudes.

\section{Analytical approach}

Before we examine the flow data from the September 2011 storm, we must explain the approach that was necessary to determine whether excess vertical/meridional flows occurred during the storm time relative to the vertical/meridional flows that would be seen during a nominal quiet period. Stoneback et al. (2011) showed that the averaged dayside meridional flows during quiet times varied between +50 and $-20 \mathrm{~ms}$ depending on longitude, local time, and season. Thus a simple observation of upward or downward ion flows after a storm onset is meaningless without comparing that flow to previous flows during quiet conditions. Also, since the quiet time vertical flows are a function of the spacecraft's orbital pass combined with the geographic location of that pass at that particular local time, then flows that are an orbit or two apart may show wildly different values even under quiet and nominal conditions. Ideally we would like to compare the orbital swath during the storm conditions with a previous pass that covered exactly the same geographic locations at exactly the same local times. So our approach was to take orbital 


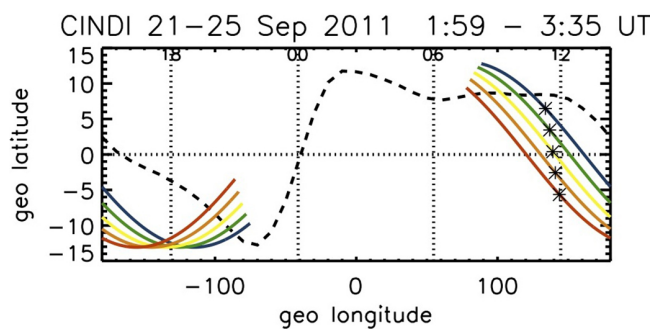

Figure 1. A diagram in geographic longitude and latitude of the ground track swaths from approximately the same universal time on the five quiet days preceding the storm event day (blue is 21 September from 01:59 UT to 02:54 UT and red is 25 September from 02:40 to $03: 35 \mathrm{UT}$ ). Each swath covers the part of the orbit from 08:00 to 22:00 local time from that particular orbit and the asterisks denote the position of the perigee. The vertical dotted lines denote the location of the local times on 21 September.

swaths that were as close to $24 \mathrm{~h}$ apart as possible and compare them. Fortunately, during this storm, the C/NOFS's orbital period divided almost evenly into $24 \mathrm{~h}$. Thus at a given location and time, the spacecraft returned to almost the same location only $10 \mathrm{~min}$ later on the next day.

Figure 1 shows an example of five individual orbital swaths covering from 08:00 SLT to 22:00 SLT plotted in geographic longitude and latitude for the five consecutive quiet days prior to the storm (21-25 September, DOY 264268). The five orbital swaths start on the right side around $+80^{\circ}$ east longitude and wrap around to the left ending around $-80^{\circ}$ east longitude. The first orbital swath from 21 September is plotted in blue and occurred between 01:59 and 02:54 UT on that day. The fifth orbital swath from 25 September is plotted in red and occurred between 02:40 and 03:35 UT on that day. The asterisks on the swaths denote the location of the perigee for each orbital swath and the vertical dotted lines indicate the location of the local times during the first day of the set, thus indicating that the perigee during these days was right around local noon. The dashed curve indicates the location of the magnetic equator. It is clear from this figure that the precession of the orbit and the slightly later time of the pass for each day causes the swaths to migrate westward and also change in latitude. This fairly wide band of orbital swaths would at first indicate there should be an equally wide variation in the vertical and meridional flows from these orbital swaths. The ranges of these orbital swaths were chosen to encompass the usable ion flow data from CINDI during this time period. During the extended solar minimum starting in 2008 only the cross track ion flow data below $550 \mathrm{~km}$ were usable because the percentage of $\mathrm{O}+$ above that altitude was too small for the ion drift meter to function accurately (Heelis et al., 2009, and Burrell et al., 2011). But by September 2011, the increased solar activity had increased the percentage of $\mathrm{O}+$ at all altitudes so that the quality of the cross track ion flow data were good up to $750 \mathrm{~km}$.
Figure 2 shows the (a) averaged vertical flows and (b) averaged meridional flows from these same five orbital swaths, but now plotted as a function of the SLT. The flows were grouped into $1 \mathrm{~h}$ local time bins and averaged. The asterisks indicate the averages and the vertical dotted lines indicate the standard deviations. The two vertical dotted lines that run the full length of the panel indicate the 12:00 and 18:00 SLT location. It is clear from both plots that the flows over the five day swaths are remarkably consistent. The variation in the average velocities as a function of the local time is much larger than either the individual standard deviation or the variance between the averages for a given hour over the five days. (Note that the large standard deviations for 19:00 through 21:00 are a result of velocities from spread F plasma bubbles in those data, but even then the variance of the averages within each hour are relatively small.) The baseline comparisons of the averaged vertical and meridional flows for the other 14 sets of orbital swaths during the five quiet days are not shown here, but in general they too show similar agreements. It should be noted that the overall shape of these averaged flows versus local time changes over the course of the day as different sets of geographic longitude and latitude are sampled. The change in the flows in the spacecraft coordinates (a) and in the magnetic coordinates (b) is slight but noticeable between the two plots. The major difference between the vertical flows, and the meridional flows is the fact that the dayside averages between 08:00 and 17:00 SLT for the meridional flows are smaller in magnitude compared to the vertical flows and the overall average of all the dayside flows is closer to zero than the same for the vertical flows. Since the $\boldsymbol{E} \times \boldsymbol{B}$ drifts would be perpendicular to the magnetic field then any differences between a storm-time flow and a quiet time flow would be clearer in the comparison of meridional flows. Thus we will only be examining the meridional flows in the rest of the paper as we compare the storm day flows against the baseline of the quiet day flows. It should also be noted that we see the downward flows in the early morning and later afternoon local times. These small downward flows are different from the expected generally small upward flows over the entire dayside (Kelly, 1989), but these downward flows are consistent with previous CINDI observations (Stoneback et al., 2011) and point out the need for a more complex understanding of the dayside meridional flows.

\section{Analysis of the 26 September 2011 storm}

On 26 September 2011, a geomagnetic storm occurred that was triggered by the arrival of a coronal mass ejection at the Earth's magnetosphere. As stated above, we have done a study of the vertical and meridional flows observed by CINDI during this storm (Hairston et al., 2013) which presents the data and results in more detail than here. Figure 3 shows the Dst (disturbance storm time) index, the solar-wind 

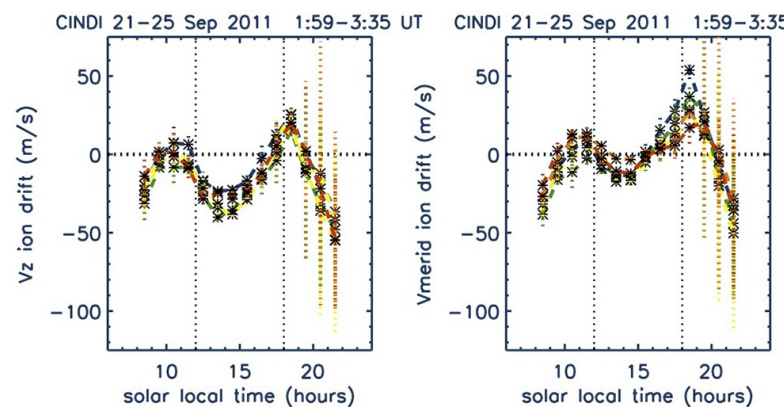

Figure 2. The left diagram shows the vertical flows from the orbital swaths in Fig. 1 after they have been grouped into $1 \mathrm{~h}$ local time bins and averaged. The asterisks denote the averaged values and the colored lines connect the averages for the same day's swath following the color scheme in Fig. 1. The vertical dots above and below the asterisks denote the magnitude of the standard deviations of the averages. Despite the $24 \mathrm{~h}$ separating each set of averages and the variation in the locations, the overall pattern of the vertical flows is quite consistent. The diagram on the right shows the same analysis for the meridional flows in the magnetic coordinate system.

dynamic pressure at the magnetopause, the IMF BZ, and the cross-polar cap potential from both hemispheres derived from the DMSP-F15, F16, F17, and F18 spacecraft for the entire seven days of this study period. The solar-wind dynamic pressure and IMF $B_{z}$ data are taken from NASA's OMNIWeb Plus website where the data were shifted to the time of their arrival at the magnetopause. The DMSP spacecraft are in polar orbits (period of $\sim 100 \mathrm{~min}$ ) that are fixed in local time, so the measured potential drop for a given polar cap pass depends on the current potential distribution and the orientation of satellite's path across that potential. Because of this, all of the measured potential drops are less than the true potential drop to some extent. Thus all the data are plotted together on the figure to show that the true potential drop would form a line that would be an upper bound on these individual measurements. F16 (green) and F17 (red) are in roughly dawn-dusk orientations, and thus tend to report the highest potentials. The purpose of this figure is to show that these parameters were very quiet during the five days prior to the storm (DOY 264-268). The data from the storm day and the recovery day (26-27 September, DOY 269-270) are shown in an expanded form in Fig. 4 for ease of examination. Figures 3 and 4 show that the storm began around midday on 26 September 2011 (DOY 269) as indicated by a pulse in the solar-wind pressure at $\sim 12: 45 \mathrm{UT}$ that triggers a short-lived increase the polar cap potential. This pressure pulse is associated with a sharp swing of $B_{z}$ to the north followed by a period of erratic swings between north and south but stay primarily northward. $B_{z}$ becomes primarily south at $\sim 14: 16 \mathrm{UT}$, becoming strongly southward $\left(B_{z}<-15 \mathrm{nT}\right)$ around 15:15 UT. The cross-polar cap potential increases throughout this period reaching a maximum potential of $210 \mathrm{kV}$ seen by F17 in the Southern Hemisphere
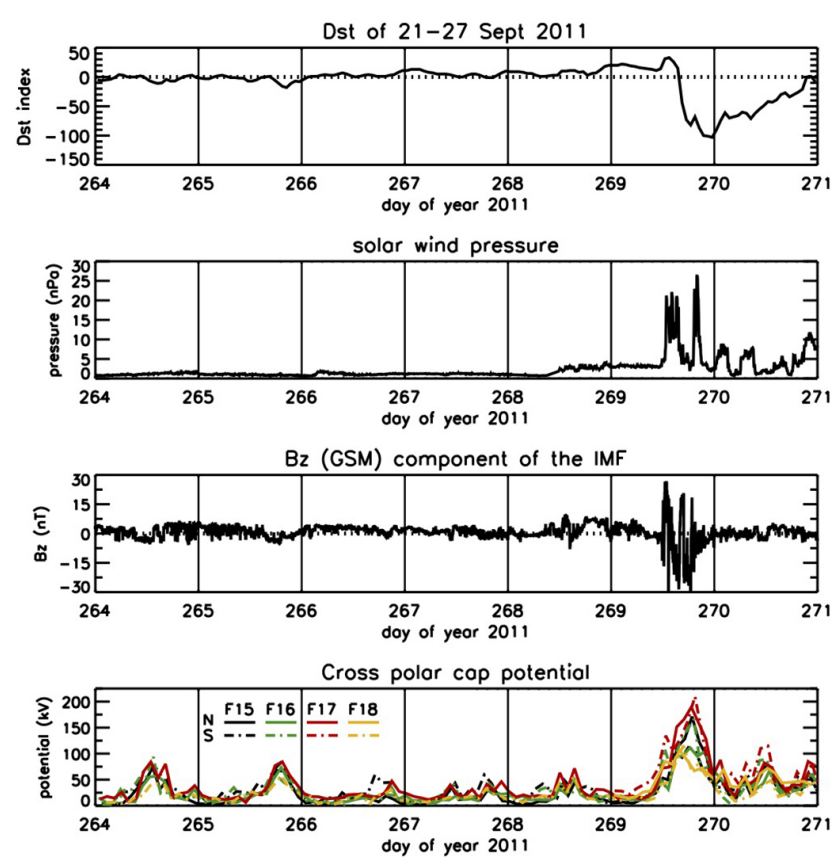

Figure 3. This figure shows (in order) the Dst index, the solar-wind pressure, the $B_{z}$ component of the IMF (in GSM coordinates), and the cross-polar cap potentials in both the Northern and Southern Hemispheres as measured by four DMSP spacecraft for the full seven days of this study. This figure emphasizes how quiet the conditions in the IMF, the magnetosphere, and the polar ionosphere were prior to the storm on 26 September (DOY 269).

around 20:00 UT on 26 September and the minimum of the Dst was $-103 \mathrm{nT}$ which was reached during hour 23 on 26 September.

Based on the Dst index going negative and the increase in the polar cap potential and the expansion of the size of the polar cap observed by the four operational DMSP spacecraft we estimate the storm onset in the polar cap occurred at about 15:30 UT on 26 September. Based on the magnitude of the Dst minima from storms in previous studies (e.g., Huang et al., 2005) and the sudden decrease in the magnitude of $B_{z}$ at the onset ( $-22 \mathrm{nT}$ drop between 15:10 and 15:40 UT), this storm should have been large enough to create a penetration electric field that would affect the equatorial ionosphere. Thus we would expect to see excess positive (upward) meridional flows during the early portion of the storm within an hour's time of the storm onset. Figure 5 shows the meridional flows from the first three dayside orbital passes of CINDI after the storm's onset (shown in black) compared to the equivalent flows (in color) from the five previous quiet days. The storm day passes in Fig. 5 cover 15:44 to $16: 39$ UT (first pass), 17:21 to 18:16 UT (second pass) and 18:57 to 19:52 UT (third pass). These figures show that no excess upward flows appears anywhere during the first four hours after the onset of the storm. In the first pass there is excess downward flow in the mid-afternoon to the post-sunset 

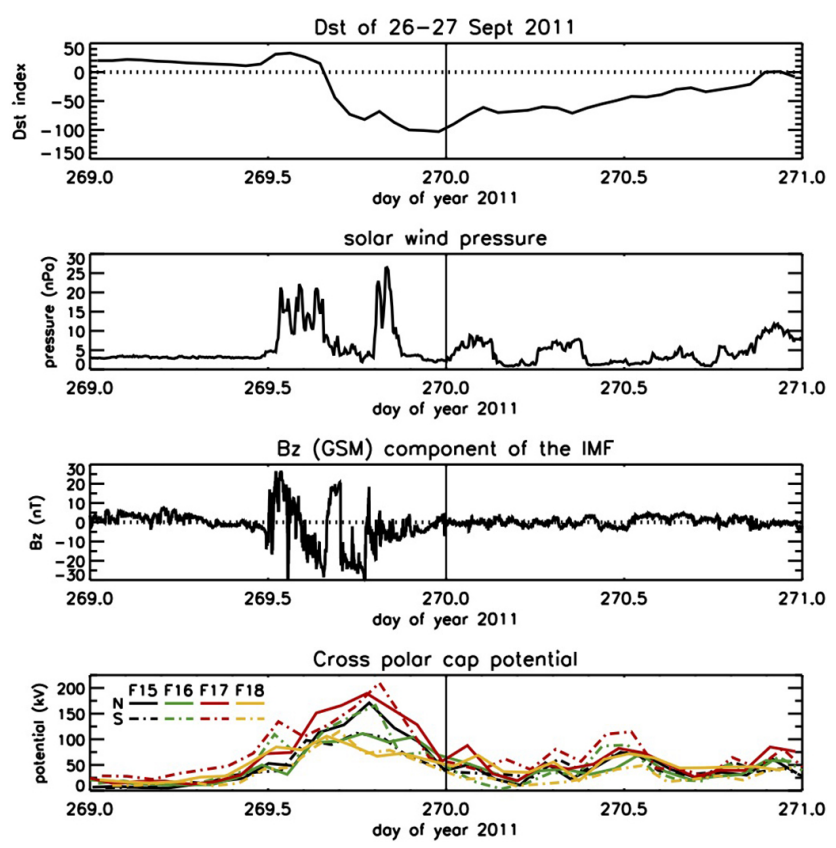

Figure 4. This figure repeats the data shown in Fig. 3 for just the storm day and recovery day (26-27 September) in an expanded form for easier examination.

region. In the second pass the excess downward flows appear in all the morning and afternoon local times. Finally, in the third passes the excess downward flows have decreased in magnitude in all local times. Figure 6 shows the fourth satellite dayside pass (20:36 to 21:29 UT) after the storm's onset and just before the Dst index reached its minimum and the recovery phase began. It is clear that the storm-time flows (in black) have a large excess downward flow that are far outside of the meridional flows expected from the envelope of the previous five days of quiet time meridional flows. This particular pass shows the largest downward deviation of storm-time flows compared to quiet time flows seen during this storm. These overall excess downward flows continue, although with smaller magnitudes, through the first three passes of 27 September (not shown). After that time all the flows observed on the recovery day returned to matching the quiet time flows. Figure 7 repeats the data from Fig. 6 with the recovery day flows added (plotted as a black dashed line) thus demonstrating how the recovery day flows have returned to roughly what they were before the storm. The fact that the recovery day flows closely match the envelope of quiet day flows, even though the recovery day orbital swath is even further westward in longitude than the storm day orbital swath, proves that the excess downward flows observed after the storm's onset are real and not an artifact of the change in the spacecraft's ground track.

Thus we are faced with a puzzle. Although this was a large geomagnetic storm that ought to have created a penetration electric field significant enough to affect the equatorial


Figure 5. These three plots show the meridional flows for the first three dayside passes after the storm onset on 26 September (plotted in black) compared to the same flows seen at the same times of day on the previous five quiet days (plotted in colors). Although the magnitude varies from pass to pass and for different local times, it is clear that all the meridional flows in these passes after the storm onset show an excess downward velocity relative to the baseline quiet day flows. The storm day passes in these figures cover 15:44 to $16: 39$ UT (first pass), 17:21 to 18:16 UT (second pass) and 18:57 to 19:52 UT (third pass).

region and produce excess upward meridional flows on the dayside, only excess downward flows were ever observed in the CINDI data between the storm onset until about $9 \mathrm{~h}$ into the recovery phase. We have performed numerical simulations using our first principles model consisting of the Rice Convection Model (RCM) coupled with the Coupled thermosphere-ionosphere-plasmasphere electrodynamics (CTIPe) model to see if we can reproduce these excess downward flows.

\section{Coupled CTIP-RCM model}

The coupled model used for this study is composed of three well-developed and tested physical models: (1) the Coupled thermosphere-ionosphere-plasmasphere electrodynamics (CTIPe) model (Fuller-Rowell et al., 1996; Millward et al., 1996, 2001); (2) the Rice Convection Model (RCM) (Wolf, 1983); and (3) the global electrodynamic solver based on the National Center for Atmospheric Research Thermosphere-Ionosphere Electrodynamics GCM (NCARTIEGCM) (Richmond et al., 1992; Richmond and Maute, 2013). The coupled model describes the electrodynamic coupling, interactions, and feedback between the inner magnetosphere and the thermosphere-ionosphere-plasmasphere 


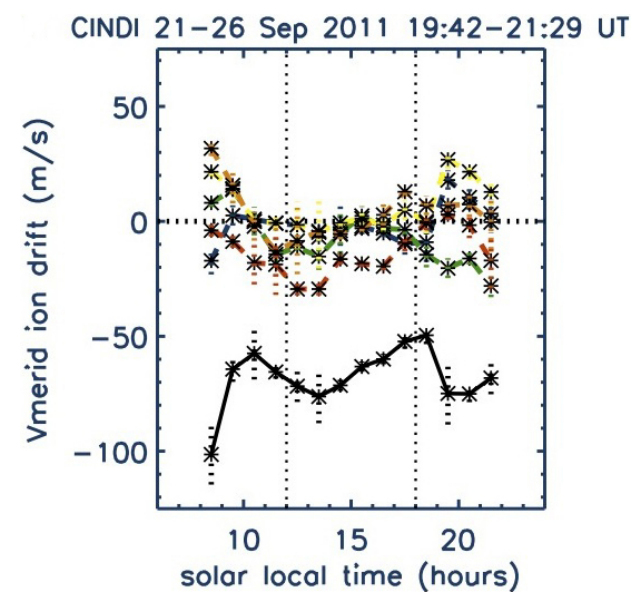

Figure 6. This plot shows the meridional flows observed during the fourth dayside pass of the satellite (20:36 to 21:29 UT) after the storm's onset (in black) compared to the baseline quiet day flows (in color). This pass demonstrates the largest excess downward flows observed during this storm event.

system, computing the time dependent, global electric field and three-dimensional plasma and neutral flows in the ionosphere and thermosphere. Therefore, it is a unique and adequate tool for our study. It includes ring currents and the polar distribution of ionospheric and field-aligned currents (FAC) associated with high-latitude convection that connect the ionosphere and magnetosphere, as well as ionospheric wind-dynamo current sources generated by the storm-time neutral wind. It is able to represent the combination of highlatitude convection and co-rotation electric fields, and the storm-time processes of prompt penetration and DD, all of which are crucial in driving the ionospheric electric field and the associated plasma flow, and joule heating and ion drag that are the main drivers of the storm-time neutral wind.

The RCM has been used to simulate prompt penetration electric fields and they have been compared with observations over a period of many years (e.g., Wolf et al., 1982; Spiro et al., 1988) to validate the model. The model calculates the ionospheric electric potential equatorward of the polar cap boundary by taking into account the self-consistent magnetosphere-ionosphere coupling, in response to polar cap potential variations specified at the boundary. The RCM has been coupled to CTIPe without losing the great capability of calculating the penetration electric field, but also by including the wind-generated ionospheric current into the potential solver to account for the DD process. Then the total electric field is used to drive the ionospheric plasmas as well as the RCM particles. The detailed description of the model coupling can be found in Maruyama et al. (2011). The horizontal resolution of the electrodynamic solver is variable in latitude with minimum $0.69 \mathrm{deg}$ in the sub-auroral region, longitude $4.5 \mathrm{deg}$, therefore, is high enough to resolve the fine structure of the region-2 FACs that are crucial in describing the prompt penetration electric field.



Figure 7. This figure presents the same data as in Fig. 6, but with the meridional flows from the pass on the recovery day (27 September) at the same time added in as a dashed black line. It is clear that the flows on the recovery day have returned to nearly those observed on the baseline quiet days, thus indicating that the excess downward flows seen on 26 September must be a result of the storm event.

\section{Model results of the 26 September 2011 storm}

In the present version of the coupled model, the auroral particle ionization profiles are evaluated from an empirical model based on the TIROS NOAA satellite measurements (FullerRowell and Evans, 1987), which is used poleward of the discrete electron aurora oval. The empirical model is driven by the power index that is similar to Kp. Auroral conductivity plays an important role in determining how electric currents flowing from the magnetosphere close through the ionosphere, therefore greatly impacting computed penetration electric field, Joule heating and ion drag, that are crucial in describing the storm-time wind and the subsequent DD electric field.

The temporal and spatial variations of the polar cap potential that is driven primarily by the solar-wind-magnetosphere interaction play a key role in computing the global electric field in the coupled model. We used an empirical model, Heelis et al. (1982) for this study because it is simply driven by the cross-polar cap potential. We need to specify the temporal variation of the polar cap potential poleward of the polar cap boundary which is determined by the magnetospheric magnetic field model.

A magnetospheric magnetic field model is required to precompute the grid for the RCM. The Hilmer and Voigt (1995) model was selected for this study. It also determines the timedependent polar cap boundary, which is the high-latitude boundary of the RCM computational domain. Furthermore, the time dependent boundary location is also required for the electrodynamic potential solver that specifies the boundary condition separating out the equatorward region of the 
self-consistent calculation from the region with the polar cap potential specified by the input model.

Previous studies showed that higher plasmasheet temperature or smaller plasmasheet density generates weaker shielding and a more penetrating electric field at lower latitudes (Spiro et al., 1988; Garner et al., 2004). As input parameters, the RCM requires $\mathrm{PV}^{5 / 3}$ (where $P$ is thermodynamic pressure; $V$ is flux tube volume, $5 / 3$ is gamma) and $\mathrm{TV}^{2 / 3}$ at $13 R_{\mathrm{E}}$ in the plasmasheet to be estimated from a statistical model, Tsyganenko and Mukai (2003) for this study.

The solar activity index, which is based on the solar radio emission at a wavelength of $10.7 \mathrm{~cm}, \mathrm{~F} 10.7=149 \times$ $10^{-22} \mathrm{~W} \mathrm{~m}^{-2} \mathrm{~Hz}^{-1}$ during this interval. While forcing from the lower atmosphere is usually overwhelmed by external forcing as soon as a magnetic storm starts, upward propagating tides from the lower atmosphere represent an additional input as described by Millward et al. (2001). We use solely the semidiurnal $(2,2)$ tidal component specified at the lower boundary of the thermospheric module at $80 \mathrm{~km}$, as was done in Maruyama et al. $(2005,2007,2011)$.

The cross-polar cap potential used to drive the coupled CTIP-RCM model as shown in the top panel of Fig. 8 was calculated from 5 min averages of ACE solar wind and IMF data using the empirical relations of Boyle et al. (1997). These data for the polar cap potential were used because of the high time resolution needed for the model, (the time step for calculating the global electric potential is $1-5 \mathrm{~s}$ ). Furthermore, DMSP spacecrafts do not always cross the exact maximum and minima of the potential. However note that the overall shape of these data agree well with the lower time resolution observations of the polar cap potential from DMSP presented in Fig. 4. The corresponding eastward electric field is also shown in Fig. 8 for the American longitude sector. This particular longitude sector was chosen as that was the longitude crossed by the spacecraft at about 16:00 SLT on the storm day pass shown as the black trace in Fig. 6 when the excess downward flows were at their greatest magnitude. The storm-time response of the eastward electric field (shown in red in Fig. 8) is calculated from the global potential dynamo solver at the reference height of $90 \mathrm{~km}$. A reference quiet time simulation is shown by the black lines, for which the cross-polar cap potential was held constant at $25 \mathrm{kV}$.

Changes in the strength of convection, most commonly caused by southward turnings of the IMF $B_{z}$ component, result in increases in the cross-polar cap potential. The penetration electric field features can be identified as sudden increase/decrease of the eastward electric field simultaneously at all three latitudes in response to the given cross-polar cap potential variations. The magnitude of the response is smaller for lower latitudes as shown in Fig. 35.2 of Maruyama et al. (2011). The coupled model describes the prompt penetration process based on a disrupt-and-restore scenario: a sudden increase in the polar cap potential drop results in a sudden increase in the dawn-dusk electric field which, in the

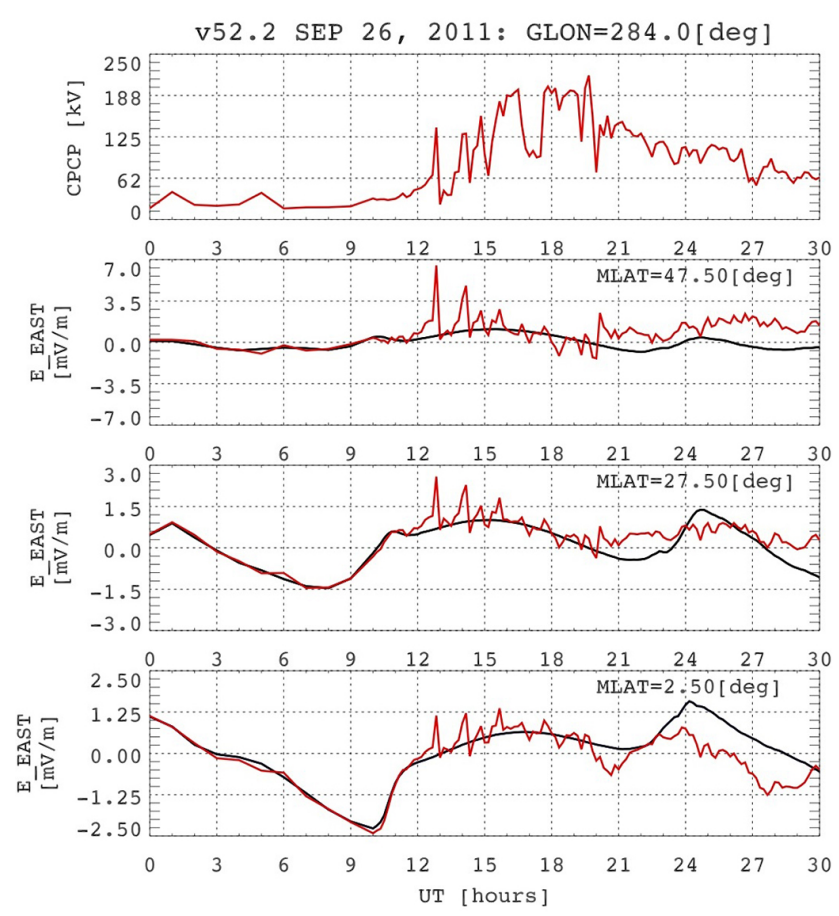

Figure 8. The universal time variation of the cross-polar cap potential (CPCP) $(\mathrm{kV})$ used to drive the coupled model simulation (top panel), the corresponding response of the eastward electric field at $90 \mathrm{~km}$ at three magnetic latitudes: $2.5^{\circ}, 27.5^{\circ}$, and $47.5^{\circ}$ are shown for the American longitude sector, at $284^{\circ}$ E geographic longitude. The red lines show the storm-time response, whereas the black curves are the quiet-time reference simulation in which the $\mathrm{CPCP}$ value is kept constant at $25 \mathrm{kV}$ for the entire simulation period. The $x$ axis starts at 00:00 UT on 26 September, 2011.

equatorial ionosphere, is westward across the night side of the Earth and eastward across the dayside.

While the magnitude becomes much smaller, the penetration effect continues into the recovery phase of the storm, indicating that the shielding is never strong during the event as previously discussed by Garner et al. (2004). The continuous penetration is unexpected from the strong shielding previously estimated by Spiro et al. (1988) in which the strong shielding was established after steady conditions were maintained for an hour or more.

Furthermore, the magnitude of the response becomes smaller as the storm progresses, since the shielding has been restored after the initial significant increase in the polar cap potential at $\sim 15: 30$ UT on 26 September, at which time the DMSP observed the significant increase in the magnitude and size of the polar cap potential as shown in the bottom panel of Fig. 4. The enhanced dawn-to-dusk electric field on the nightside brings the shielding layer closer to Earth by reconfiguring the ring current particles under the action of $\boldsymbol{E} \times \boldsymbol{B}$ and gradient/curvature drift.

In response to the sudden drop of the polar cap potential at around 19:50 UT on 26 September, the overshielding effect 
happens: it is characterized by the sudden westward drift enhancement simultaneously at all latitudes. While mid- and low-latitude electric fields recover upward immediately afterwards due to the following increase in the polar cap potential, the signature of the DD process can be identified at the equator starting at around 20:00 UT on 26 September; the equatorial electric field variation started to deviate and reverse from the quiet time values. The DD effect decreases the equatorial $\boldsymbol{E} \times \boldsymbol{B}$ drift during the day and the evening prereversal enhancement, as demonstrated in Plate 5 of FullerRowell et al. (2008) obtained from the standalone CTIPe calculation (without prompt penetration effect). Joule heating has been gradually deposited over high latitude since the storm commencement. The pressure gradient generated by the high-latitude energy input creates the equatorward wind surge and alters the global circulation. Ionospheric electric current driven by the storm-time wind tends to build up the charge distribution opposite from that during quiet time, as already discussed in the introduction.

\section{Discussion}

The original purpose of our research was to identify and quantify the excess upward meridional ion flows on the dayside equatorial region in response to the penetration electric field during a geomagnetic storm. However results for this storm showed only excess downward flows after the IMF southward turning and storm's onset at about 15:30 UT on 26 September. Excess downward ion flows on the dayside can be generated either by a northward turning of the IMF, which causes overshielding, and/or by a disturbance dynamo (DD). While the equatorial ionosphere can react almost immediately in response to changes in the IMF and polar cap potential, the disturbance dynamo takes at least a couple of hours after the beginning of the storm to affect the lower latitude regions. There was a period of strongly northward IMF during the storm (about 16:45 to 17:35 UT on 26 September, see Fig. 4) this occurred after the first excess downward flows were observed and, as the period of northward IMF was relatively short lived, it cannot be the cause of all the excess downward flows observed during the storm. The model results suggest the largest excess downward flows, the ones observed in Fig. 6 just before the beginning of the recovery phase, were most likely caused by the combination of the overshielding effect and the disturbance dynamo that had manifested itself five hours after the storm onset. Although the model run for this storm captured this large excess downward flow observed in Fig. 6, the model results are smaller in magnitude than the observed flows.

The uncertainties associated with the values of the model input parameters make it challenging for the model to accurately predict the timescale and magnitude of the disturbance dynamo effect. In particular, the uncertainty of the high-latitude forcing, such as the polar cap potential and auroral precipitation have a significant impact on estimating the high-latitude energy input and the resultant disturbance of the neutral wind. The temporal and spatial variations of the polar cap potential and auroral precipitation are not consistent in the model: the polar cap potential is derived from the relationship with the solar-wind parameters based on Boyle et al. (1997), whereas the auroral precipitation is based on the TIROS/NOAA measurements. Furthermore, the size of the polar cap potential is determined by the magnetospheric magnetic field model based on Hilmer and Voigt (1995) model which is also not consistent with the auroral precipitation.

The continuous downward flows shown in Fig. 5 before the largest downward flow in Fig. 6 were not reproduced by the model. Instead it produced upward flows in response to sudden increases in cross-polar cap potential (under-shielding condition) as seen in Fig. 8. Thomas et al. (2013) showed that the IMF $B_{y}$ effect on the polar cap potential pattern lasted until 19:50 along with the strong $B_{z}$ southward. IMF $B_{y}$ effect rotates the polar cap potential clockwise. Mannucci et al. (2014) showed that the IMF $B_{y}$ effect tends to generate reduced TEC variations as one would normally expect from the IMF $B_{z}$ variations alone. They suggested that the penetration electric field at the equator that is mainly responsible for creating the enhanced TEC is reduced due to the IMF $B_{y}$ effect. One could imagine that the rotated polar cap potential pattern can produce different LT variations from those that are produced by the usual dawn-to-dusk two-cell patterns. This IMF $B_{y}$ effect is not included in the model: maximum and minimum of the electric potential are always located at dawn and dusk, respectively. It would be interesting to investigate how the IMF $B_{y}$ effect on the polar cap potential pattern would alter the penetration process at the equator in a future study.

The overshielding effect characterized by the sudden decrease of the polar cap potential at $\sim 16: 30-19: 10 \mathrm{UT}$, and $\sim 19: 50$ UT in the top panel of Fig. 8 did not seem to produce significant westward field enhancement in the equatorial latitude electric field as much as the observed flows from CINDI would imply. It could be caused by the uncertainty in the plasmasheet and magnetic field model used as input to the RCM component of the coupled model. For example, there is a possibility that the degree of distortion of the inner magnetospheric magnetic field caused by the dawn-dusk convection enhancement is not very well reproduced by the Hilmer and Voigt (1995) magnetic field model. Furthermore, the strong enhancement in the solar-wind dynamic pressure starting at 12:45 and 19:15 UT accompanied by the large southward $B_{z}$ seen in Fig. 4 could have resulted in a strong compression of magnetosphere and the dayside magnetopause being pushed earthward, which might not have been captured well by the magnetic field model. since the model does not directly depend on the solar-wind dynamic pressure variation. The time variation of the magnetospheric magnetic field configuration has a significant 
impact on the penetration electric field, as suggested by $\mathrm{Fe}$ jer et al. (1990) as magnetospheric reconfiguration effect: continuously changing magnetic field tends to inhibit shielding to be established, thus penetration effect tends to last longer. In order to verify all the above possible scenarios, one would need a comprehensive validation of the magnetospheric magnetic field, and plasmasheet conditions in the model during the event. Furthermore, a comprehensive sensitivity study would be required in order to improve our understanding of how sensitive the storm-time response of the equatorial plasma flow is to various kinds of model input parameters and their different combinations as discussed above. Such comprehensive validation and sensitivity studies are beyond the scope of this initial comparison study. Furthermore, for the purpose of computational convenience, the RCM assumes that the ionospheric magnetic field is a dipole aligned with the planetary spin axis. Therefore, caution is required when comparing the model to observations because the coupled model is limited in describing the longitudinal variation of the storm-time response of the electric fields (i.e., plasma flows).

This is only the first storm we have studied by comparing the CINDI data to the coupled CTIP-RCM modeling results. There are dozens of other storms that occurred after September 2011 that are candidates for such analysis. We are planning on repeating this type of study on these storms in order to build a better understanding of the dynamics of the equatorial ionosphere and provide a better explanation of these excess downward flows observed by CINDI.

Acknowledgements. We wish to acknowledge the ACE Science Center and their website and NASA's OMNIWeb Plus website for the IMF data used in this paper, and the World Data Center for Geomagnetism at Kyoto University, Japan for the Dst index data. The work at the University of Texas at Dallas was supported by NASA grant NNX10AT02G. Work by N. Maruyama was supported by NASA grant NNX09AN58G and by NSF grants AGS 1042258 and AGS 1103149.

Topical Editor J. Klenzing thanks two anonymous referees for their help in evaluating this paper.

\section{References}

Blanc, M. and Richmond, A. D.: The ionospheric disturbance dynamo, J. Geophys. Res., 85, 1669-1686, 1980.

Boyle, C. B., Reiff, P. H., and Hairston, M. R.: Empirical polar cap potentials, J. Geophys. Res., 102, 111-125, doi:10.1029/96JA01742, 1997.

Burrell, A. G., Heelis, R. A., and Stoneback, R. A.: Latitude and local time variations of topside magnetic field-aligned ion drifts at solar minimum, J. Geophys. Res., 116, A11312, doi:10.1029/2011JA016715, 2011.

Fejer, B. G., Spiro, R. W., Wolf, R. A., and Foster, J. C.: Latitudinal variation of perturbation electric fields during magnetically disturbed periods: 1986 SUNDIAL observations and model results,
Ann. Geophys., 8, 441-454, 1990, http://www.ann-geophys.net/8/441/1990/.

Fejer, B. G., Jensen, J. W., Kikuchi, T., Abdu, M. A., and Chau, J. L.: Equatorial Ionospheric Electric Fields During the November 2004 Magnetic Storm, J. Geophys. Res., 112, A10304, doi:10.1029/2007JA012376, 2007.

Fejer, B. G., Jensen, J. W., and Su, S.-Y.: Seasonal and longitudinal dependence of equatorial disturbance vertical plasma drifts, Geophys. Res. Lett., 35, L20106, doi:10.1029/2008GL035584, 2008.

Fuller-Rowell, T. and Evans, D. S.: Height-integrated pedersen and hall conductivity patterns inferred from the tiros/noaa satellite data, J. Geophys. Res., 92, 7606-7618, 1987.

Fuller-Rowell, T., Rees, D., Quegan, S., Moffett, R., Codrescu, M., and Millward, G.: A coupled thermosphere-ionosphere model (ctim), Report, STEP, 1996.

Fuller-Rowell, T. J., Richmond, A., and Maruyama, N.: Global modeling of storm time thermospheric dynamics and electrodynamics, Midlatitude Ionospheric Dynamics and Disturbances, AGU Geophys. Monograph Series, 181, 187-200, doi:10.1029/181GM18, 2008.

Garner, T. W., Wolf, R. A., Spiro, R. W., Burke, W. J., Fejer, B. G., Sazykin, S., Roeder, J. L., and Hairston, M. R.: Magnetospheric electric fields and plasma sheet injection to low L-shells during the 4-5 June 1991 magnetic storm: Comparison between the Rice Convection Model and observations, J. Geophys. Res., 109, A02214, doi:10.1029/2003JA010208, 2004.

Hairston, M. R., Coley, W. R., and Stoneback, R.: Vertical and meridional equatorial ion flows observed by CINDI during the 26 September 2011 storm, J. Geophys. Res.-Space, 118, 52305243, doi:10.1002/jgra.50411, 2013.

Heelis, R., Lowell, J., and Spiro, R.: A model of the high-latitude ionospheric convection pattern, J. Geophys. Res., 87, 63396345, 1982.

Heelis, R. A., Coley, W. R., Burrell, A. G., Hairston, M. R., Earle, G. D., Perdue, M. D., Power, R. A., Harmon, L. L., Holt, B. J., and Lippincott, C. R.: Behavior of the $\mathrm{O}+/ \mathrm{H}+$ transition height during the extreme solar minimum of 2008, Geophys. Res. Lett., 36, L00C03, doi:10.1029/2009GL038652, 2009.

Hilmer, R. V. and Voigt, G.-H.: A magnetospheric magnetic field model with flexible current systems driven by independent physical parameters, J. Geophys. Res., 100, 5613-5626, 1995.

Huang, C.-S.: Continuous penetration of the interplanetary electric field to the equatorial ionosphere over eight hours during intense geomagnetic storms, J. Geophys. Res., 113, A11305, doi:10.1029/2008JA013588, 2008.

Huang, C.-S., Foster, J. C., and Kelley, M. C.: Long-duration penetration of the interplanetary electric field to the low-latitude ionosphere during the main phase of magnetic storms, J. Geophys. Res., 110, A11309, doi:10.1029/2005JA011202, 2005.

Jaggi, R. K. and Wolf, R. A.: Self-consistent calculation of the motion of a sheet of ions in the magnetosphere, J. Geophys. Res., 78, 2852-2866, 1973.

Kelly, M. C.: The Earth's Ionosphere: Plasma Physics and Electrodynamics, Academic Press Inc-Harcourt Brace Jovanovich, Publishers, San Diego CA, 1989.

Kelley, M. C., Makela, J. J., Chau, J. L., and Nicolls, M. J.: Penetration of the solar wind electric field into the magne- 
tosphere/ionosphere system, Geophys. Res. Lett., 30, 1158, doi:10.1029/2002GL016321, 2003.

Mannucci, A. J., Crowley, G., Tsurutani, B. T., Verkhoglyadova, O. P., Komjathy, A., and Stephens, P.: Interplanetary magnetic field $B_{y}$ control of prompt total electron content increases during superstorms, J. Atmos. Sol.-Terr. Phys., 115-116, 7-16, doi:10.1016/j.jastp.2014.01.001, 2014.

Maruyama, N., Richmond, A. D., Fuller-Rowell, T. J., Codrescu, M. V., Sazykin, S., Toffoletto, F. R., Spiro, R. W., and Millward, G. H.: Interaction between direct penetration and disturbance dynamo electric fields in the storm-time equatorial ionosphere, Geophys. Res. Lett., 32, L17105, doi:10.1029/2005GL023763, 2005.

Maruyama, N., Sazykin, S., Spiro, R. W., Anderson, D., Anghel, A., Wolf, R. A., Toffoletto, F., Fuller-Rowell, T. J., Codrescu, M. V., Richmond, A. D., and Millward, G. H.: Modeling storm-time electrodynamics of the low latitude ionospherethermosphere system: Can long lasting disturbance electric fields be accounted for?, J. Atmos. Sol.-Terr. Phys., 69, 1182-1199, doi:10.1016/j.jastp.2006.08.020, 2007.

Maruyama, N., Fuller-Rowell, T. J., Codrescu, M. V., Anderson, D., Richmond, A. D., Maute, A., Sazykin, S., Spiro, R. W., Wolf, R. A., Toffoletto, F. R., and Millward, G. H.: Modeling the storm time electrodynamics, Springer-International Association of Geomagnetism and Aeronomy (IAGA) Division II Book on Aeronomy of the Earth's Atmosphere and Ionosphere, edited by: Abdu, M. A., Pancheva, D., and Bhattacharyya, A., 2011.

Millward, G., Moffett, R. J., Quegan, S., and Fuller-Rowell, T. J.: A coupled ionosphere-thermosphere-plasmasphere model, ctip., in: Handbook of Ionospheric Models, edited by: Schunk, R. W., Report, STEP, 1996.

Millward, G. H., Muller-Wodarg, I. C. F., Aylward, A. D., FullerRowell, T. J., Richmond, A. D., and Moffett, R. J.: An investigation into the influence of tidal forcing on $\mathrm{F}$ region equatorial vertical ion drift using a global ionosphere-thermosphere model with coupled electrodynamics, J. Geophys. Res., 106, 24733 24744, doi:10.1029/2000JA000342, 2001.
Richmond, A. D. and Maute, A.: Ionospheric electrodynamics modeling in Modeling the Ionosphere/Thermosphere System, edited by: Huba, J., Schunk, R., and Khazanov, G., Am. Geophys. Union monograph, 2013.

Richmond, A. D., Ridley, E. C., and Roble, R. G.: A thermosphere/ionosphere general circulation model with coupled electrodynamics, Geophys. Res. Lett., 19, 601-604, 1992.

Scherliess, L. and Fejer, B. G.: Storm time dependence of equatorial disturbance dynamo zonal electric fields, J. Geophys. Res., 102, 24037-24046, doi:10.1029/97JA02165, 1997.

Spiro, R. W., Wolf, R. A., and Fejer, B. G.: Penetration of highlatitude-electric-field effects to low latitudes during SUNDIAL 1984, Ann. Geophys., 6, 39-50, 1988, http://www.ann-geophys.net/6/39/1988/.

Stoneback, R. A., Heelis, R. A., Burrell, A. G., Coley, W. R., Fejer, B. G., and Pacheco, E.: Observations of quiet time vertical ion drift in the equatorial ionosphere during the solar minimum period of 2009, J. Geophys. Res., 116, A12327, doi:10.1029/2011JA016712, 2011.

Thomas, E. G., Baker, J. B. H., Ruohoniemi, J. M., Clausen, L. B. N., Coster, A. J., Foster, J. C., and Erickson, P. J.: Direct observations of the role of convection electric field in the formation of a polar tongue of ionization from storm enhanced density, J. Geophys. Res.-Space, 118, 1180-1189, doi:10.1002/jgra.50116, 2013.

Tsyganenko, N. A. and Mukai, T.: Tail plasma sheet models derived from Geotail particle data, J. Geophys. Res., 108, 1136, doi:10.1029/2002JA009707, 2003.

Wolf, R. A.: The quasi-static (slow-flow) region of the magnetosphere, in Solar-Terrestrial Physics: Principles and Theoretical Foundations, edited by: Carovillano, R. L. and Forbes, R. L., D. Reidel, Hingahm, MA, 303-368, 1983.

Wolf, R. A., Harel, M., Spiro, R. W., Voigt, G.-H., Reiff, P. H., and Chen, C.-K.: Computer simulation of inner magnetospheric dynamics for the magnetic storm of July 29, 1977, J. Geophys. Res., 87, 5949-5962, doi:10.1029/JA087iA08p05949, 1982. 